\title{
CHRONIC STRONGYLOIDIASIS IN A TRANSPLANT RECIPIENT
}

M Benavides-Nieto', T Sáinz-Costa', A Vázquez-Pérez', S Pérez-Muñoz', J Bustamante', M García López-Hortelano', J Villota Arrieta', MJ Mellado-Peña'

'Hospital La Paz, General Paediatrics and Infectious and Tropical Diseases Department, Madrid, Spain.

\section{BACKGROUND}

- Strongyloidiasis is a parasitic infection caused by a nematode, endemic in tropical and subtropical countries.

- Recently, autochthonous cases have been described of Spain's east coast.

- It can occur asymptomatically or cause skin, gastrointestinal or pulmonary involvement, and immunosuppressed subjects are at risk of hyperinfestation and disseminated disease.

- Nowadays, it is not included in the systematic screening for patients before initiation of immunosuppression and there are not guidelines for its treatment and prophylaxis in high-risk subjects

\section{CASE PRESENTATION}

7-year-old boy

- Mitochondrial complex IV deficiency

- Multivisceral transplant and splenectomy at 3 years, under treatment with Tacrolimus and Metilprednisolone

- Spanish origin, resident in Madrid, summers on the Spanish east coast

At 4years old he presents:

- recurrent urticaria (no suspection of GVHD)

- eosinophilia $2490 / \mathrm{mm} 3$, IgE $3200 \mathrm{mg} / \mathrm{dL}$.

- Positive Strongyloides stercoralis serology

$\rightarrow$ Diagnosis: Strongiloidiasis
$>$ Treatment with Ivermectin with clinical improvement, initial decrease of eosinophilia (I 190/mm3) and serological titers.

$>$ Subsequent reactivation (Eosinophilia 2000/mm3, lgE $>5000 \mathrm{mg} / \mathrm{dl}$, higher serological titers) led to a new treatment cycle, not completed due to drug interaction.

$>14$ months after the first cycle, combined treatment with Ivermectin-Albendazole was administered for 10 days.

$>4$ months later, a new cycle of combined treatment, accompanied with a delayed hypersensitivity reaction to Albendazole.

$>$ Due to persistence of clinical and analytical alterations, he received again Ivermectin for 7 days and desensitization against Albendazol was performed.

$>$ He received a new cycle Albendazol-Ivermectina, with improvement of serological titres and eosinophilia.

$>$ Subsequently, he has continued with prophylactic Ivermectin (monthly).

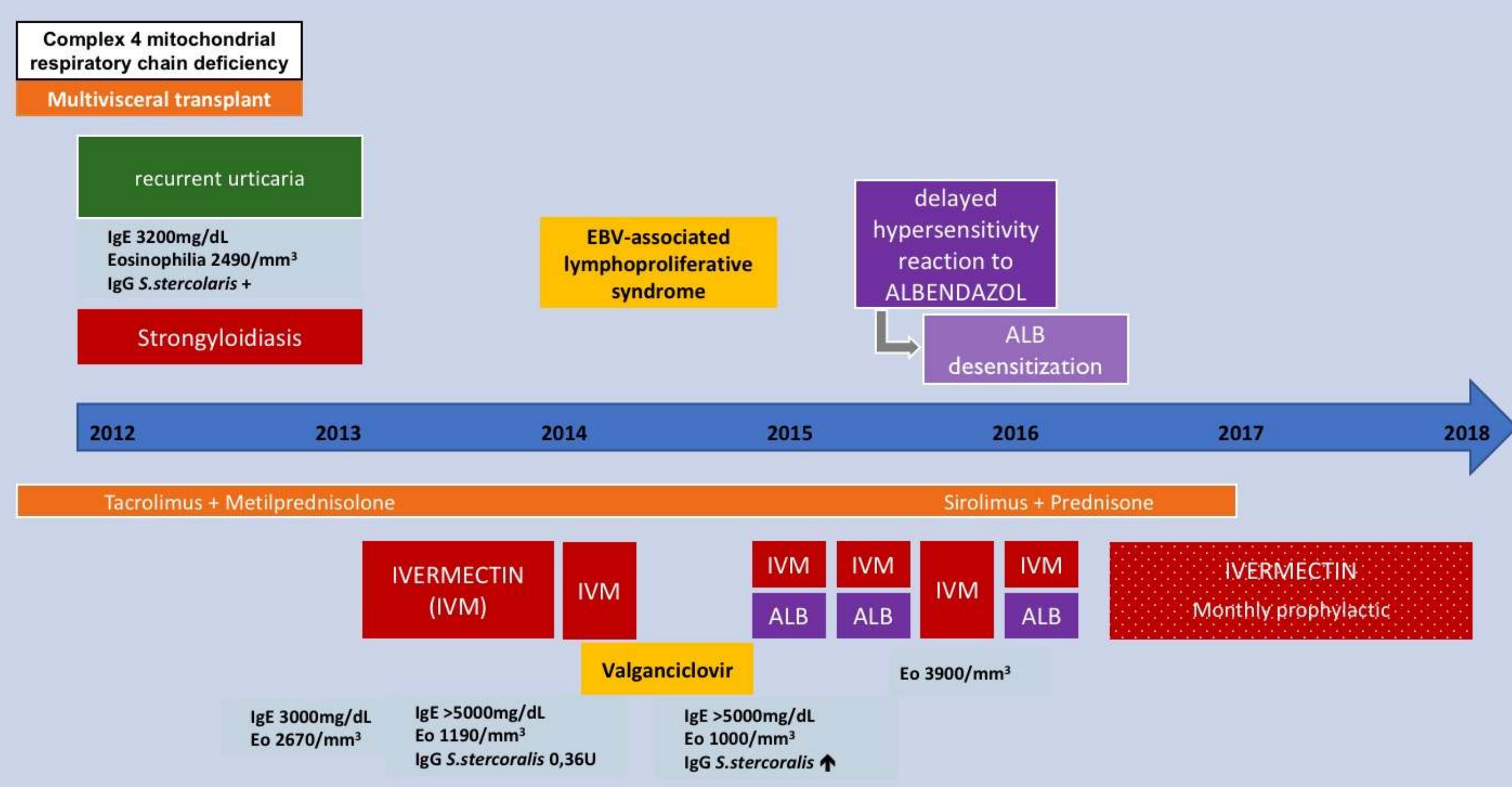

\section{DISCUSSION}

- Strongyloidiasis should be included in the systematic screening prior to immunosuppression, given the potential severity of the condition and the difficulties in treatment. 